\title{
Development of Distributed-type Linear Generator with Damping Control
}

\author{
Takamitsu YAMAMOTO \\ Researcher,
}

\section{Toshiaki MURAI}

Chief Researcher, Maglev Technology Div.,Maglev Development Dept.

\author{
Hitoshi HASEGAWA \\ Researcher,
}

\begin{abstract}
Hiroshi YOSHIOKA
Manager, Maglev Technology div., Maglev Development Dept.

\author{
Shunsuke FUJIWARA \\ Senior Researcher,
}

Maglev Development Dept.

\section{Satoru HATSUKADE}

Engineer, Traction Control G.,

The superconducting Maglev system suspended by EDS intrinsically has negative magnetic damping. In order to improve the magnetic damping, we used a linear generator by controlling the power factor of the current in the linear genetator coils. We developed a PWM converter and a simulator ( using Micro Cap VI) for this control. This paper describes how to control the PWM converter and subsequently the power factor and the result of confirmation of this control method through simulation and synthetic bench tests. We can now control the PWM converter and the power factor without affecting the output power.
\end{abstract} Vehicle Technology Development Dept.

Keywords : Auxiliary power supply, linear generator, PWM converter, controlling the power factor,
improving the ride comfort

\section{Introduction}

The superconducting Maglev system suspended by Electro-Dynamic Suspension ( EDS ) intrinsically has negative magnetic damping 1) 2) 3). This factor degrades the ride comfort of the Maglev system. Therefore, a method to use a linear generator is proposed to improve the negative damping of $\operatorname{EDS}^{4)}$. This method is to control the phase ( power factor) between the induced voltage and the currents in the linear generator coils in order to generate a damping force ${ }^{5)}$. This method is realized by controlling the PWM converter of the linear generator to change the phase angle of the current in the linear generator coil in proportion to the signal of bogie vibration velocity.

However, the output generator power reduces when the phase angle is changed, because the power factor is reduced. Therefore, this method is effective when sufficient output power is generated. We have not yet confirmed if the power generated stably when controlling the phase and if the PWM converter follows properly the signal to control the phase.

This paper reports the calculation result of improving the ride comfort, result of simulation of PWM converter operation and result of this operation in bench tests of an experimental circuit.

\section{Structure and principle of linear generator}

\subsection{Damping control method using linear generator}

Fig.1 shows the structure of Distributed-type Linear Generator. The linear generator coils are installed on each surface of outer vessel of superconducting magnet. Currents are induced in the levitation ground coils shaped (like a figure 8 ) when the Maglev vehicle runs. So the
Maglev vehicle can be levitated by the force between the alternating magnetic field generated by the currents in the levitation ground coils and the direct magnetic field of the superconducting magnet. Because the guideway is composed of discrete ground coils, we can observe a harmonic alternative magnetic field on the vehicle. So we can obtain currents induced by setting the linear generator coils ( shaped like a figure 8 , the same as the levitation ground coils ) from that harmonic alternative magnetic field. We can utilize the power for the load on the vehicle by converting the induced current into direct current by the PWM converter.

The PWM converter can control the phase angle and the amplitude of the current in the linear generater coils by the method explained in section 2.4 . When the phase angle is $0^{\circ}$ (or the power factor is unity), the vertical force by the current in the linear generater is 0 . And when

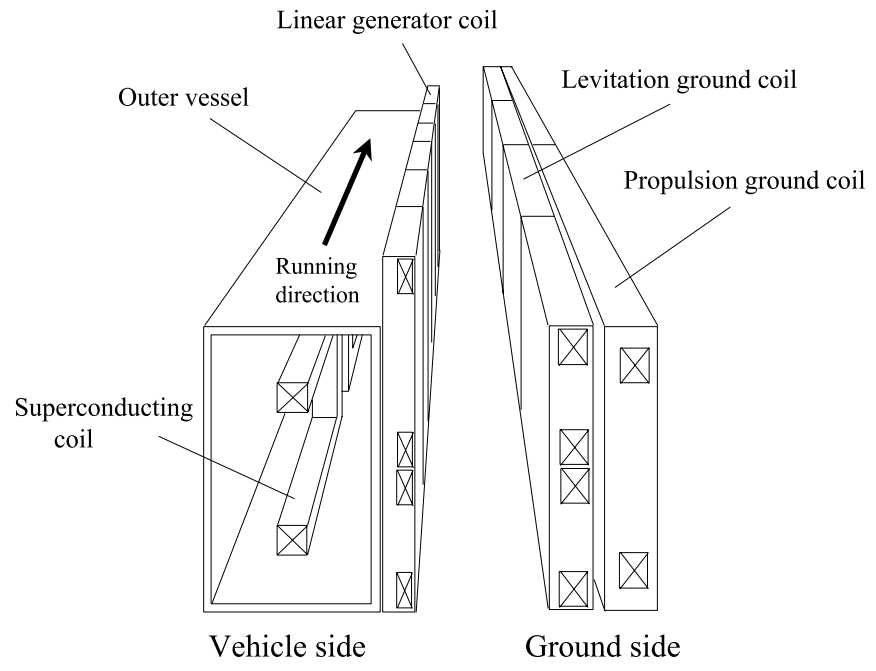

Fig. 1 Structure of Distributed-type Linear Generator 
the phase angle is $\pm 90^{\circ}$, the maximum absolute vertical force is generated.

Consequently, we can use this force to reduce the bogie vibration by controlling the phase angle according to the signal of the bogie vibration velocity.

\subsection{Superconducting magnet for Distributed-type Linear Generator}

Fig. 2 shows the outside drawing of the superconducting magnet for Distributed-type Linear Generator.

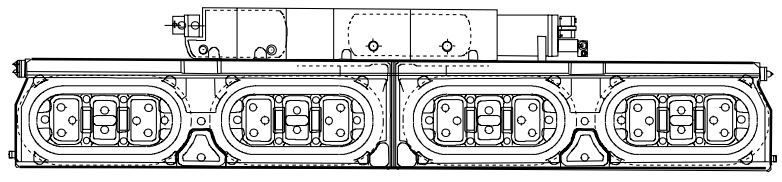

Fig.2 Superconducting magnet for Distributed-type Linear Generator

It is required for the surface of this superconducting magnet facing the ground coils to keep a $20 \mathrm{~mm}$ space for the linear generator coils. So the distance between the cross sectional center of the superconducting coil and the surface of outer vessel has been reduced from that of a conventional magnet without changing the distance between the superconducting coil and levitation coil. To improve power collection, conductive materials should not be near the linear generator coil ( an eddy current is induced in it to reduce the linkage flux of linear generator coils ). Because the outer vessel of the superconductive magnet which installs the linear generator coils is made of aluminum, this superconducting magnet is designed as follows, in order to increase the power collection performannce.

(a) There are a lot of hollows in the outer vessel.

(b) The upper and linear generator side of the outer vessel is cut.

(c) The linear generator coils are higher than the outer vessel.

\subsection{Distributed-type Linear Generator coils}

There are fifteen linear generator coils on the superconducting magnet. Fig. 3 shows the outside drawing of the linear generator coils.

In order to make coils as light as possible, the windings are concentrated near the coil surface. And we use strand wires for the windings in order to avoid increase of $\mathrm{AC}$ resistance. To reduce the weight, the back side of the linear generator coils facing the superconducting magnet is composed of a honeycomb structure. The linear generator coil positioned near the guidance wheel is lower than that in Fig. 3.

\subsection{Operation principle of PWM converter}

Fig. 4 shows an outline of the main circuit of the Distributed-type Linear Generator.

In terms of electrical characteristics, we can regard the linear generator coils as a power source ( whose induced voltage and frequency change with the Maglev vehicle velocity ), resistance and inductance. This imped-

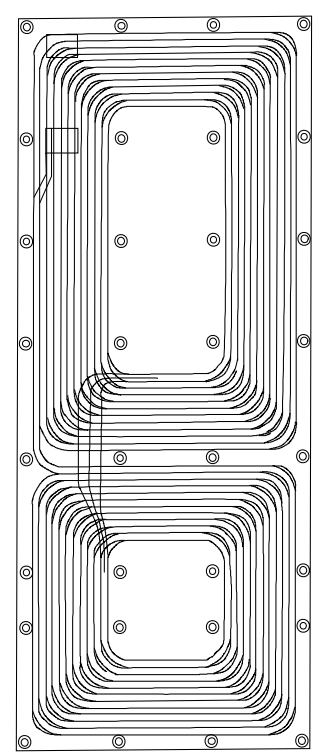

Fig. 3 Distributed-type Linear Generator coil

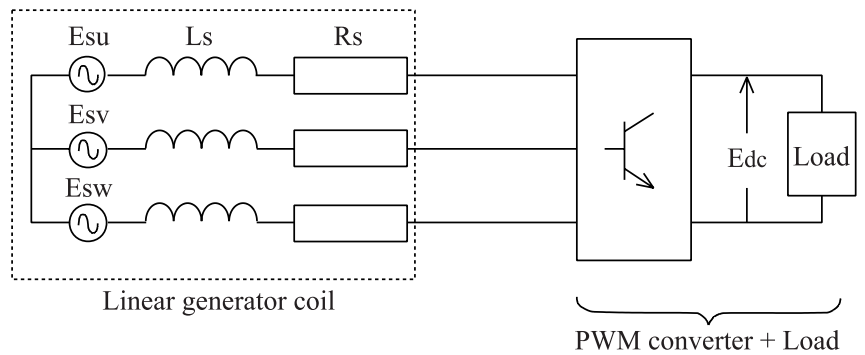

Fig. 4 Outline of the main circuit

ance of linear generator coil is assumed to be Rs+jwLs. A power converter is necessary to supply power to the DC loads on the vehicle from AC power generated by linear generator coils. We use a PWM converter for this purpose. We regard the PWM converter and load as an

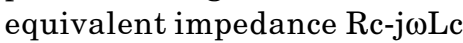

Fig. 5 shows a simplified equivalent one-phase circuit.

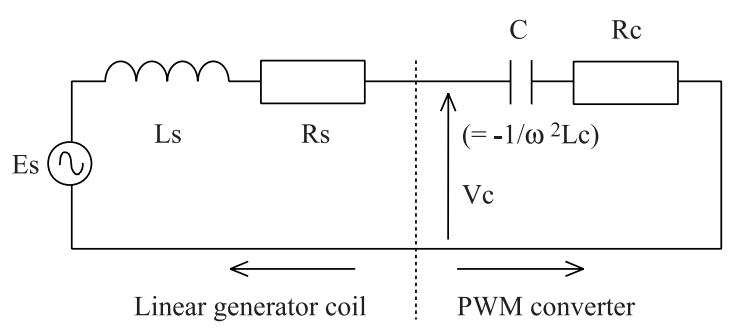

Fig. 5 Equivalent one-phase circuit

To obtain the maximum power, it is necessary to make the power factor unified. It is realized when the following conditions for the equivalent impedance of the PWM converter are satisfied.

$\mathrm{Rc}=\mathrm{Rs}$ (maximum power condition)

$\mathrm{Lc}=\mathrm{Ls}$ (power factor unity condition) 
If we put the equivalent impedance of the PWM converter as Rc-j $\omega \mathrm{Lc}$, the input voltage of the PWM converter $(\mathrm{Vc})$ is expressed by the equation (1).

$$
\begin{aligned}
& \mathrm{Vc}=(\mathrm{Rc}-\mathrm{j} \omega \mathrm{Lc}) \times \mathrm{Ic} \\
& \mathrm{Ic}: \text { Input current of the PWM converter }
\end{aligned}
$$

Here, " $\mathrm{j}$ " means a phase angle lead of $90^{\circ}$, so we can quickly calculate " Vc " by using the same phase current and another phase current ${ }^{6)}$.

We can receive enough power when Maglev vehicles run at high velocity. In this case, the output voltage exceeds the allowable voltage if the power collection continues under the condition of maximum power and unified power factor. So the output voltage must be controlled. The output power " $\mathrm{P}$ " is expressed by the following equation (2).

$$
\mathrm{P}=3 \times\left(\frac{\mathrm{es}}{\mathrm{Rs}+\mathrm{Rc}}\right)^{2} \times \mathrm{Rc} \times \alpha \times \cos ^{2} \theta
$$

es: Induced voltage of linear generator coils,

$\alpha$ :Efficiency, $\cos \theta:$ Power factor

Therefore, output voltage control is realized by adjusting the output power by controlling " Rc " in the equation (2).

In order to generate a damping force, it is necessary to control the phase angle of the input current. The phase angle " $\theta$ " satisfies the next expression.

$$
\begin{aligned}
& \theta=\tan ^{-1} \frac{\omega(\mathrm{Lc}-\mathrm{Ls})}{\mathrm{Rs}+\mathrm{Rc}} \\
& \omega: \text { Angular frequency }
\end{aligned}
$$

We can control the phase angle by adjusting ' Lc ' in the equation (3). Fig. 6 shows a phase diagram, and Fig. 7 a flow chart of PWM converter control.

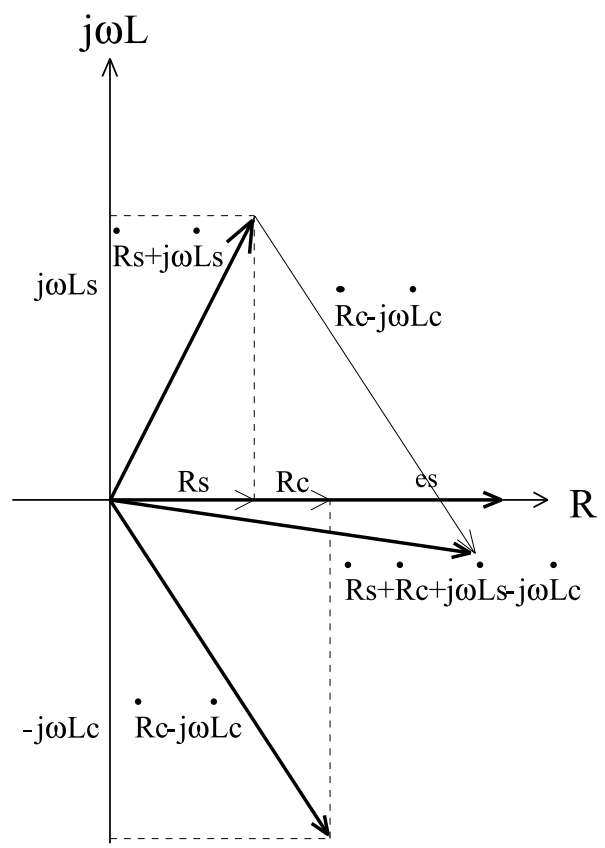

Fig. 6 Phase diagram

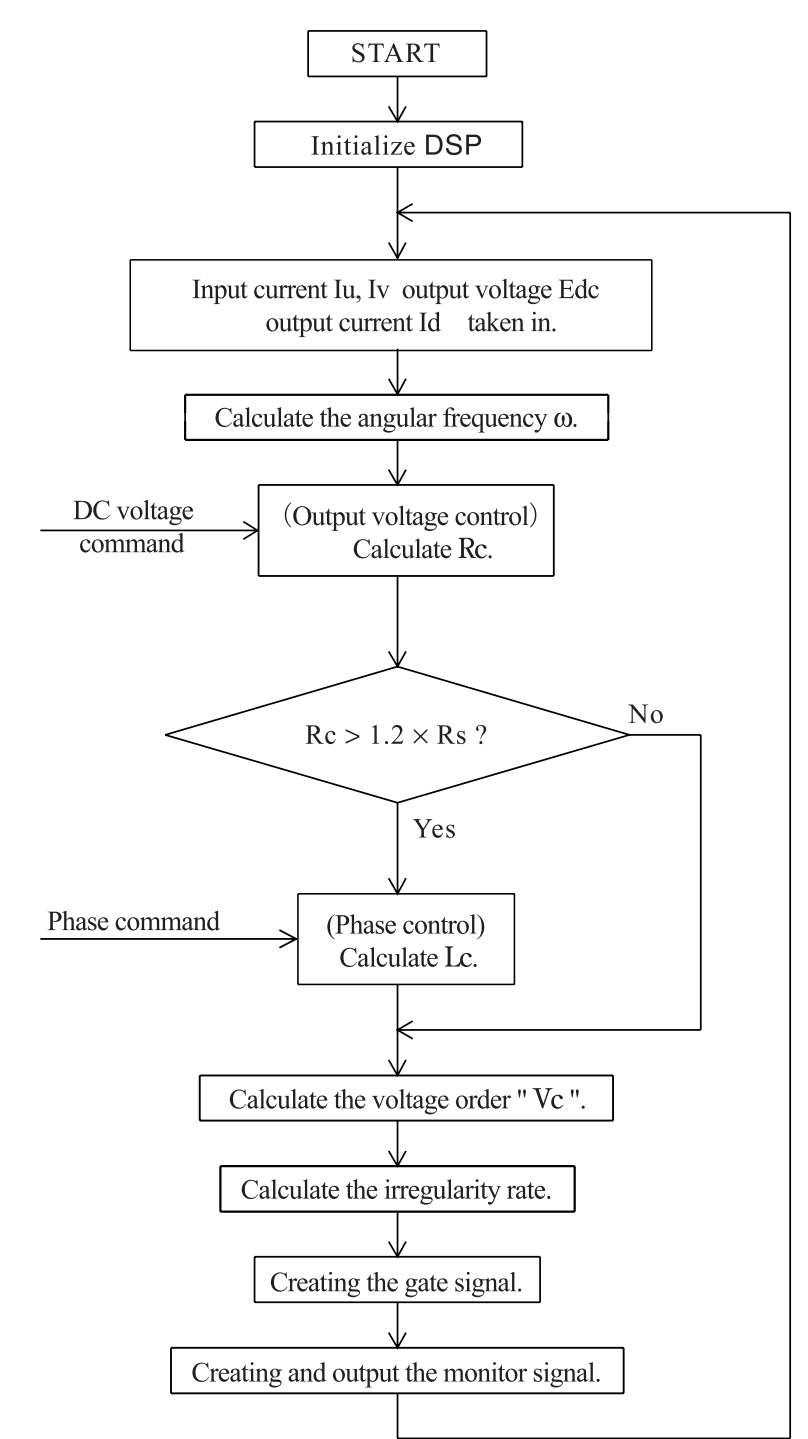

Fig. 7 Flow chart of the PWM converter control

\subsection{Expected effect of damping control}

The damping force is estimated to be about $2 \mathrm{kN}$ at the linear generator coil current of $350 \mathrm{~A}$, winding of 11 turns and controlling phase limit of $\pm 30^{\circ}$ We examined how we can improve the ride comfort by using this force. As a preliminary study, we used the following simple rule.

We use ' - ' maximum damping force at the vertical velocity of bogie $>0$.

We use ' + ' maximum damping force at the vertical velocity of bogie $<0$.

This rule is equal to the one when a friction force works between the bogie and absolute space.

We calculate the improvement effect of the ride-comfort level ( the level which is calculated from the RMS acceleration wave-form multiplied by the ride-comfort filter ). Fig. 8 shows the reducing effect. In this figure, the horizontal axis is the ride-comfort level without damping control. The reducing effect vs maximum control force is 
shown in Fig. 9 ( at the ride-comfort level of $90 \mathrm{~dB}$ without damping control ).

We can see that an improvement of ride comfort, more than $1.5 \mathrm{~dB}$, is expected under the $92 \mathrm{~dB}$ in Fig. 8. And we can improve the ride comfort further if we can increase the damping control force in Fig. 9.

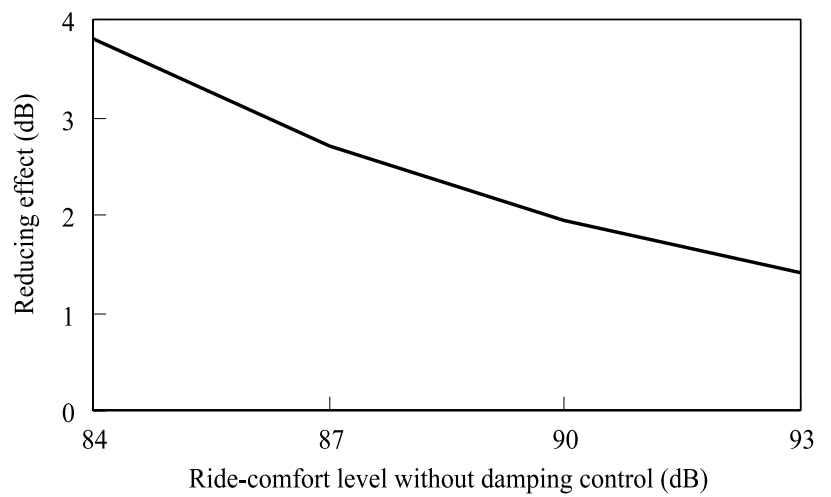

Fig. 8 Relation between the reducing effect and ride comfort level without damping control

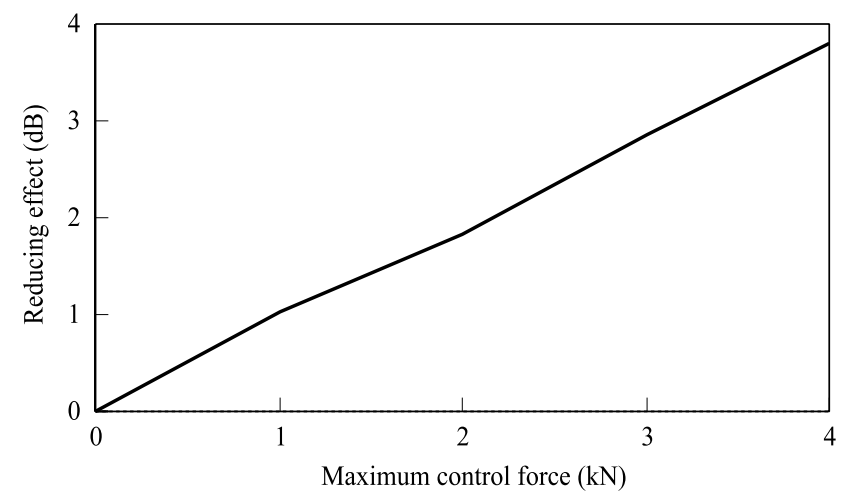

Fig. 9 Relation between the reducing effect and maximum damping control force (at the ridecomfort level of $90 \mathrm{~dB}$ without damping control)

\section{Confirmation by simulation of PWM converter operation}

\subsection{Simulation software}

We used Micro Cap VI ( Pspice series electric circuit simulator manufactured by Spectrum Co. in the US ) for simulation of PWM converter operation. We can easily use this software, because it:

(a) Can be used for mixed analog and digital circuit simulation.

(b) Can output the consequence of transient analysis in text files.

(c) Has a lot of device libraries.

(d) Can be used for simulation by a personal computer ( not a workstation).

Fig. 10 shows a sample of simulation circuit.
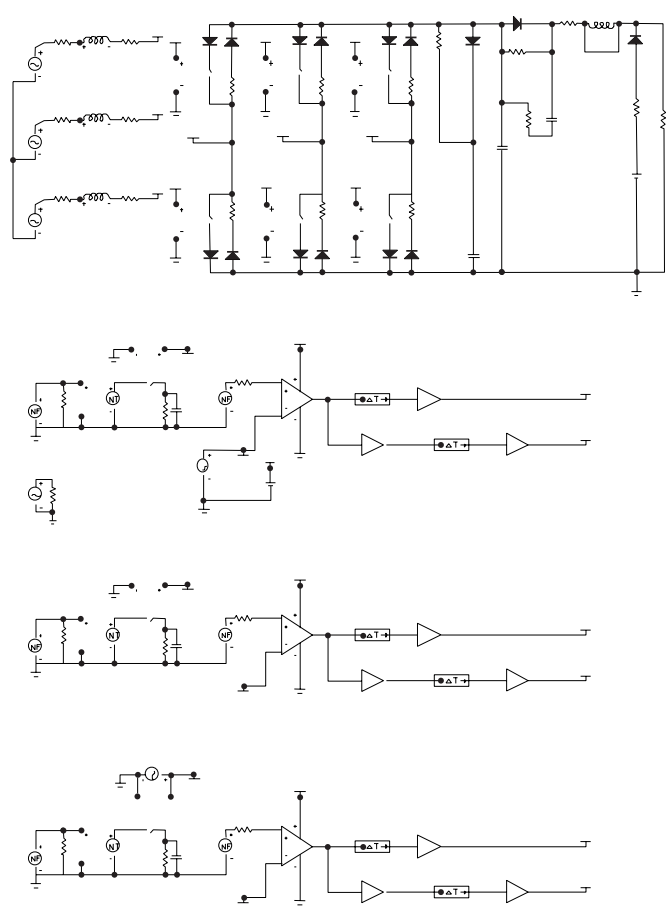

Fig. 10 Sample of simulation circuit

\subsection{Results of the simulation}

Fig. 11 shows the waveform of the induced voltage and the current in the linear generator coils simulated at about $500 \mathrm{~km} / \mathrm{h}$, phase control of $15 \mathrm{~Hz}, \pm 30^{\circ}$ (sine wave).

Fig. 12 shows the consequence of phase control and the output power.

From these figures, we can see that the output power is obtained stably and the output phase angle is controlled satisfactorily. There is a small discrepancy on the + side between the consequence and the phase control command.

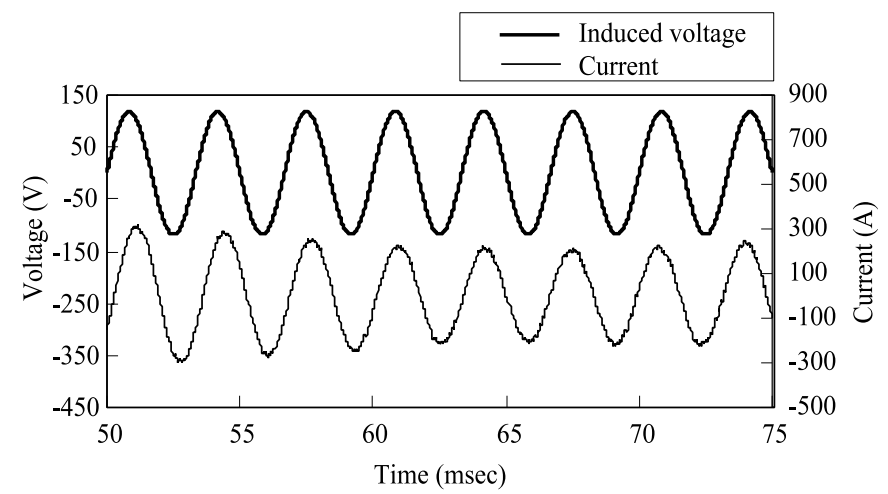

Fig. 11 Simulation of phase control (Induced voltage, current in the linear generator coils) 


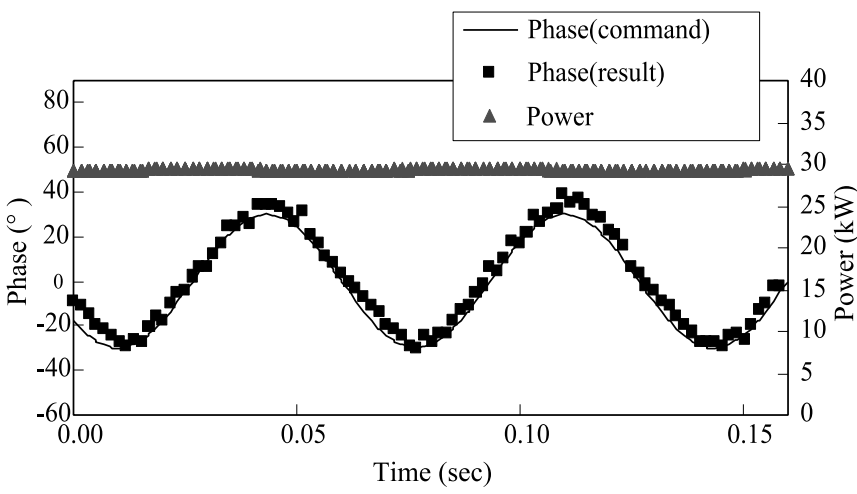

Fig. 12 Simulation of phase control (Phase, output power)

\section{Results of the bench test}

\subsection{Construction of test equipment}

We used an electro-magnetic vibration simulator ( a magnetic field generating simulater with coils set to generate the sixth harmonic magnetic field ) and an inverter to generate an alternate magnetic field which is generated when the Maglev train runs.

By arranging the linear generator coils to face these exciting ground coils, we generated an induced voltage which simulated the real induced voltage of Maglev train running. Fig. 13 shows the construction of the bench test circuit.

Table 1 shows the constant values of induced voltage, resistance, inductance of the linear generator coils. Table 2 shows the specification of the PWM converter.

This bench test used 48 cell series-connected $12 \mathrm{~V}$ $30 \mathrm{Ah}$ lead storage batteries. The resistance to simulate the load was $15 \Omega$.

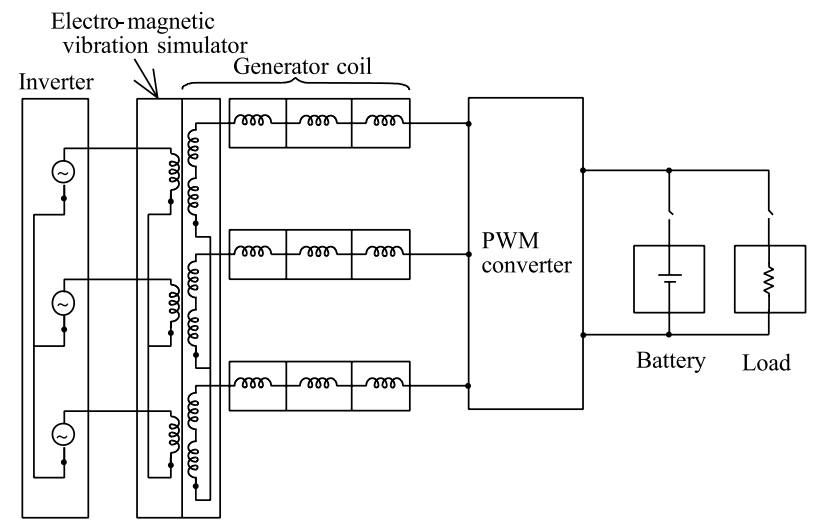

Fig. 13 Construction of bench test circuit

Table 1 Constant value of the linear generator coils (at $300 \mathrm{~Hz}$ )

\begin{tabular}{|l|l|}
\hline Resistance & $0.0863 \Omega$ \\
\hline Inductance & $0.373 \mathrm{mH}$ \\
\hline Induced Voltage & $83.75 \mathrm{~V}_{\mathrm{rms}}$ (at heavy condition) \\
\hline
\end{tabular}

Table 2 Main features of PWM converter

\begin{tabular}{|l|c|}
\hline Size & $1000 \times 504 \times 350 \quad(\mathrm{~mm})$ \\
\hline Weight & $90 \mathrm{~kg}$ \\
\hline Capacity of output & $30 \mathrm{~kW}$ \\
\hline Input Voltage & $200 \mathrm{~V}(\mathrm{max})$ \\
\hline Input Current & $300 \mathrm{~A}(\mathrm{max})$ \\
\hline Output Voltage & $410 \sim 660 \mathrm{~V}$ \\
\hline OutputCurrent & $50 \mathrm{~A}(\max )$ \\
\hline Cooling system & Fan-cooling \\
\hline
\end{tabular}

\subsection{Experiment results}

Fig. 14 shows the characteristics of power supply capacity without damping control. The result at $300 \mathrm{~Hz}$ is the value when the output voltage is controlled. We can see that the power factor is nearly 1 and power efficiency is about 0.9 . We confirm that the frequency to give an output power above the prescribed $25 \mathrm{~kW}$ is about $185 \mathrm{~Hz}$ (velocity of $300 \mathrm{~km} / \mathrm{h}$ ) .

Fig. 15 shows the relation between frequency and the

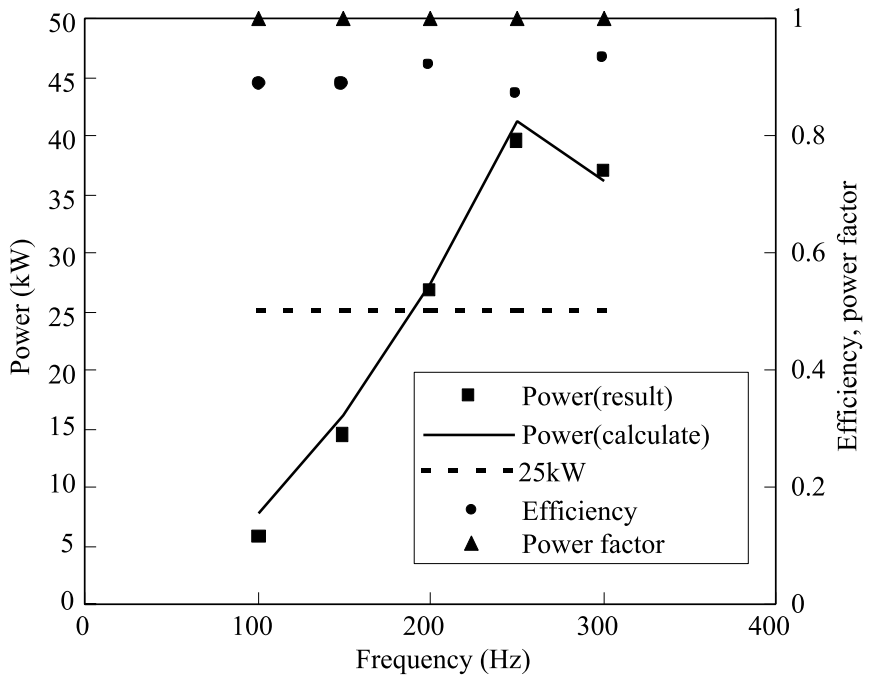

Fig. 14 The characteristics of the output power

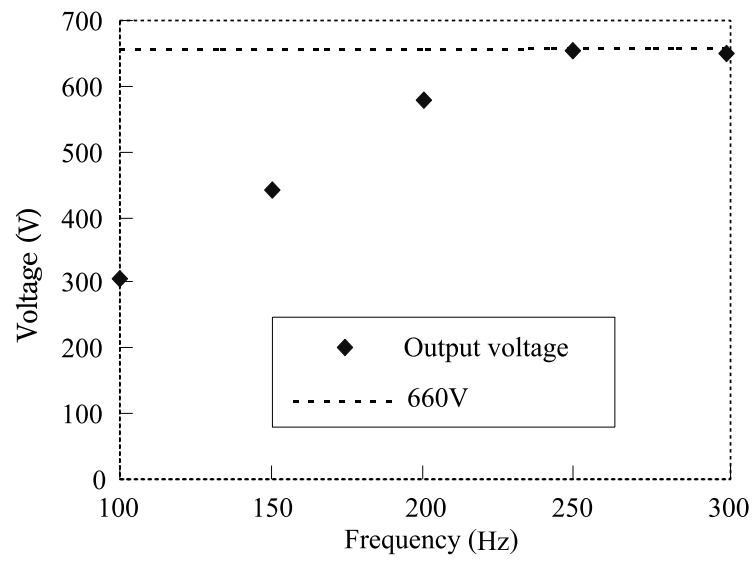

Fig. 15 Relation between frequency and the output voltage 
output voltage at the command of output voltage of $660 \mathrm{~V}$. We can see that the value of output voltage doesn't exceed the commanded voltage after the output power reaches its rated output.

Fig. 16 shows the result of phase control at the velocity of $500 \mathrm{~km} / \mathrm{h}$ and the phase control command of $15 \mathrm{~Hz} \pm$ $30^{\circ}$. In this condition, we can obtain sufficient collection power, and see that the output power is in stable agreement with the result of the simulation in spite of phase control command.

We can see that the response of phase is a little different when the phase control command is less than zero in the same way as in the simulation. The reason for this difference is explained as follows.

(a) There is a difference between the linear generator coil inductance Ls and set-up inductance of PWM converter Lc, so that there is a little phase difference to the " + " side when the control command of the phase angle is 0 degrees. In addition, the phase control command is limited to $\pm 32^{\circ}$.

(b) There is a dead -time ( $3 \mu \mathrm{sec}$ ) which cases the phase difference, in order to avoid shortening the main circuit arms.

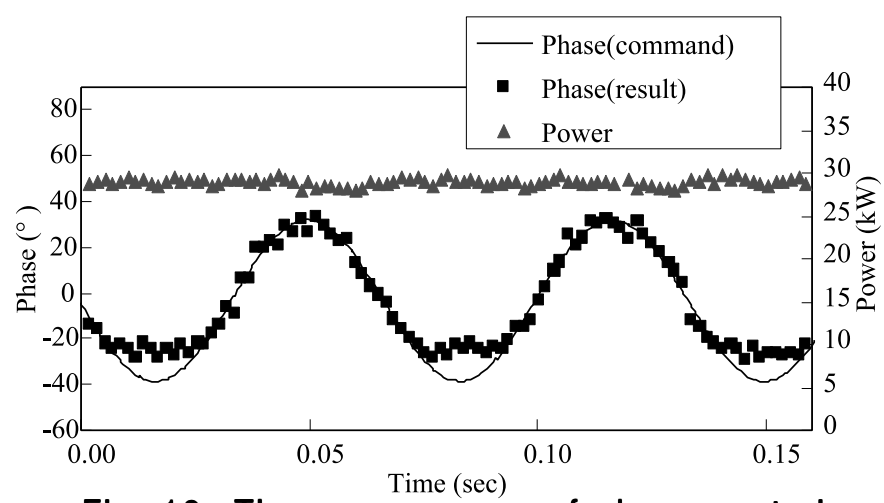

Fig. 16 The consequence of phase control experiment

\section{Conclusions}

Through simulation and bench tests of the phase control of PWM converter, we obtained the follow conclusions.

- We confirmed that the frequency to generate power over $25 \mathrm{~kW}$ is about $185 \mathrm{~Hz}$ ( velocity of $300 \mathrm{~km} / \mathrm{h}$ ).

-We obtained the same phase control result from the simulation which used MICRO CAP VI and bench test.

- We can see that the output voltage is properly limited by the command of output voltage when large output power is generated.
- In the bench test of phase control to obtain damping force, the PWM converter follows the command of phase control signals, and there is no large fluctuation in the output power.

In this study, we examined the operation of PWM converter of Distributed-type Linear Generator to obtain damping force in order to improve the ride comfort, and we confirmed that the PWM converter follows the command of phase control signal. At the next step, we will develop the logic and system on how to make the command of phase control signal from the vehicle dynamics information. And we examine the method to increase the damping force to improve ride comfort.

\section{Acknowledgements}

The authors express gratitude for the members of Toyo Denki Seizo Corporation for their assistance in a developing the PWM converter used for the study.

\section{References}

1)Yamada, T., Iwamoto, M. and Ito, T.: "Magnetic Damping Force in Inductive Magnetic Levitation System for High Speed Trains (in Japanese)", Trans. IEE of Japan , Vol.94-B, No.11, pp.49-54, 1974.1

2)Fujiwara, S. and Yamaguchi, H.: "Magnetic Damping of Electro-dynamic Levitation System (in Japanese)", Linear Drive Trans. IEE of Japan, LD-92-55, pp.47-54, 1992.7

3)Higashi, K., Ohashi, S., Osaki, H. and Masada, E.: "Magnetic Damping of the Electrodynamic Suspension Type Superconducting Levitation System (in Japanese)", Trans. IEE of Japan, Vol.117-D, No.8, pp.1015-1023, 1997.8

4)Murai, T., Hasegawa, H. and Fujiwara, S.: "Improvement of Inductive Power Collection in Null-flux EDS Maglev (in Japanese)", Trans. IEE of Japan, Vol.117D,No.1,pp.81-90 (1997.1)

5)Fujiwara, S., Murai, T. and Hasegawa, H.: "Magnetic Damping Method of EDS System Using Power Collection Coil (in Japanese)", Trans. IEE of Japan, Vol.119D, No.2, pp.254-259, 1999.2

6)Watanabe, T., Ueno, H., Takeuchi, N., Nagabuchi, S., Hayashi, H. and Saitou, Y.,: "PWM Converter Using Instantaneous Current Detection For Linear Generator of Maglev Vehicle (in Japanese)", Trans. IEE of Japan, Vol.115-D, No.3, pp348-353, 1995.3 